ROCZNIKI PSYCHOLOGICZNE/ANNALS OF PSYCHOLOGY

2019, XXII, $1, \quad 35-52$

DOI: http://dx.doi.org/10.18290/rpsych.2019.22.1-3

MICHAŁ OLSZANOWSKI ${ }^{\mathrm{a}}$

MICHAŁ PARZUCHOWSKI ${ }^{\mathrm{b}}$

ALEKSANDRA SZYMKÓW ${ }^{\mathrm{b}}$

${ }^{a}$ SWPS University of Social Sciences and Humanities, Warsaw, Poland

${ }^{\mathrm{b}}$ SWPS University of Social Sciences and Humanities, Faculty in Sopot, Poland

Center of Research on Cognition and Behavior

\title{
WHEN THE SMILE IS NOT ENOUGH: THE INTERACTIVE ROLE OF SMILING AND FACIAL CHARACTERISTICS IN FORMING JUDGMENTS ABOUT TRUSTWORTHINESS AND DOMINANCE
}

People often assess other people's personality traits merely based on their emotional expression or the physical features of their faces. In this paper we review the evidence of biases when formulating judgments of trustworthiness and confidence from two types of facial characteristics. One line of evidence documents the influence of emotional expressions representing an individual's motivational state and reflecting agents' intentions. People's judgment about the trustworthiness or attractiveness of others largely depends on the emotions expressed. The second line of evidence describes how facial appearance (e.g., cues of physical strength or resemblance to one's own face) affects the inferences of personality traits. The two experiments described in this paper investigated the interplay between these two factors (i.e., facial features and emotional expression) and their combined influence on social judgments. We hypothesized and tested how both facial features conveying trustworthiness (vs. dominance) and a smiling (vs. neutral) expression influence judgments of trustworthiness and confidence (Study 1). We also tested the influence of facial resemblance in an interaction with a smiling individual when forming judgments (Study 2). We found that relatively static facial features conveying trust had more impact on judgments of trustworthiness than emotional expressions, yet emotional expressions seem to be more impactful for judgments of dominance. The results of both studies are discussed from a sociocognitive perspective.

Keywords: face; facial features; smile; similarity; impression formation; judgments of trustworthiness; judgments of dominance.

Corresponding author: MiCHA£ OLSZANOWSKI - SWPS University of Social Sciences and Humanities, ul. Chodakowska 19/31,03-815 Warszawa, Poland; e-mail: molszanowski@swps.edu.pl 


\section{INTRODUCTION}

Emotional expressions are mostly used to signal behavioral intentions (Todorov, 2017). While a person planning on stealing something may falsely signal positive intentions (with a smile), someone offering true help may not smile at all but have a genuinely "trustworthy face." When do people use or ignore these kinds of cues from facial features in order to detect other people's true intentions? Or could a smile be a valid cue of people's intentions and their personality regardless of their other facial features?

It is well accepted in the literature that faces are perceived and recognized as a whole stimulus (Tanaka \& Simonyi, 2016). More precisely speaking, the face is perceived not as a random combination of separate features (e.g., eyes, nose, and mouth), but rather as a spatially organized sum of features. However, these specific facial features and the effects of their configural spacing play an important role in the recognition of an individual's face. Importantly, individual physical facial features along with emotional expressions help people to assess the personality traits of others (Hassin \& Trope, 2000; Todorov, Said, Engell, \& Oosterhof, 2008; Zebrowitz \& Montepare, 2008). Despite the fact that both facial characteristics - expression and features - are apparently simultaneously managed in the process of face perception (Bruce \& Young, 2012), the degree to which they influence our judgments may differ depending on the nature of the judgment. For example, it seems reasonable to claim that when making judgments of trustworthiness people should focus to a greater extent on relatively stable facial features compared to more context-dependent ones, such as other people's emotional expressions.

Emotional expressions and face morphology can undoubtedly influence the way we judge other people (Oosterhof \& Todorov, 2008). Expressions of anger or joy are the most effective means to signal an individual's motivational state (see Horstmann, 2003 for a review), which consequently lead us to behave accordingly towards them. We tend to avoid people who express anger, and we are attracted to those who express positive emotions (Van Kleef, Van Doorn, Heerdink, \& Koning, 2011). Numerous data have suggested that efficient decoding of emotions can be an exceptionally quick and adaptive way of evaluating other people's behaviors (Haxby, Hoffman, \& Gobbini, 2000). If so, should our impression about other people's characteristics depend solely on the emotions they express?

Common logic would suggest that, in contrast to permanent physical aspects, an emotional premise is of a situational nature and cannot be treated as a reliable 
source of such fundamental personality judgments. Indeed, based on the literature it is possible to list several physical facial features that individuals take into the account in the process of trait inference (e.g., babyfaceness, signs of physical strength, or similarity to a familiar person; Hassin \& Trope, 2000; Todorov et al., 2008; Zebrowitz \& Montepare, 2008; Verosky \& Todorov, 2010). However, numerous other studies suggest that people also tend to judge the social traits of others according to their facial emotional expressions (Knutson, 1996; Montepare \& Dobish, 2003; Winkielman, Olszanowski, \& Gola, 2015). Our take on this literature is that this is, in fact, the problem of dynamic (emotional expressions) vs. static (facial features) facial characteristics; these have mostly been investigated separately, which makes it impossible to establish which of them is crucial in what aspects of impression formation each of them makes a difference. A single paper that directly addresses both factors simultaneously suggests that emotional expression could be used to more or less voluntarily modulate the visibility of the features allowing others to make inferences about social traits (Gill, Garrod, Jack, \& Schyns, 2014).

There is convergent evidence suggesting that judgments of trustworthiness from faces are rapidly and spontaneously computed (Todorov, Pakrashi, \& Oosterhof, 2009). This complements evolutionary approaches emphasizing that communion-related qualities are of adaptive value - deciding whether someone can be trusted or not is important in order to predict his or her reciprocal intentions (Ybarra et al., 2008). Thus, when deciding about trustworthiness, relying on contextually changing expressions of emotions would not be enough for an optimal judgment. As was shown by Hehman and colleagues (Hehman, Flake, \& Freeman, 2015), social evaluations performed during multiple presentations that are based on dynamic cues (e.g., intentions inferred from emotional expression) are more likely to change as the cues change, while evaluations based on static facial structures (e.g., abilities inferred from a face's width-to-height ratio) are more consistent (Hehman et al., 2015). We can therefore expect that more static facial features (such as face length, cheekbone or jawbone width, as well as their specific configuration that shows similarity to the person making the judgment) should be more crucial here.

Facial expressions constitute a vital premise pertaining to the sender's internal state and intention (Horstmann, 2003). Deciphering these "intentions" enables making more accurate predictions about the interlocutor's reactions, and this in turn makes it possible to plan one's own behaviors better. The clarity and unambiguity of an actor's facial expressions permits quick categorizing and effective reaction formation by an observer and may at the same time present an 
essential basis for formulating attributive judgments, attitudes, and convictions about others (Knutson, 1996; Montepare \& Dobish, 2003; Hess, Adams, \& Kleck, 2009). Findings from a statistical principal component analysis indicated that specific trait inferences could be represented within a 2D space defined by valence/trustworthiness and power/dominance evaluation of faces. Inferences along these dimensions are based on a similarity to expressions signaling whether the displaying person should be approached (i.e., a smiling individual or a trustworthy face) or avoided (i.e., an angry individual or a dominant face) and to features signaling physical strength, respectively, indicating that trait inferences from faces originate in functionally adaptive mechanisms (Todorov et al., 2008; Oosterhof \& Todorov, 2008; but see also the Behavioral Ecology View of facial displays, in Fridlund, 1994; Crivelli \& Fridlund, 2019). This was also corroborated in the study by Winkielman and colleagues (Winkielman et al., 2015; Olszanowski, Kaminska, \& Winkielman, 2018), where participants were asked to make social judgments of persons presenting various emotion expression levels, smoothly ranging from anger to joy. The data collected unequivocally suggest that faces expressing joy (i.e., smiling ones) were evaluated as more trustworthy than angry faces.

\section{The present studies}

In the current paper, we argue that social judgments are made on the basis of the aforementioned facial characteristics: dynamic (a smiling expression) and static (physical features - face morphology). They interact together as cues for the evaluation of basic social traits, namely communion/trust (as represented by trustworthiness judgments) and agency/dominance (as represented by confidence judgments; Abele \& Wojciszke, 2007, 2014; Wojciszke \& Abele, 2008; Todorov et al., 2008). More specifically, we focused on contrasting faces with highlighted physical features when being neutral or smiling. The idea behind such a setting is that a smile can signal affiliation. To smile, then, is to invite and maintain social bonds by communicating approachability and appeasement (Ekman, 2007, but see Martin, Rychlowska, Wood, \& Niedenthal, 2017). As a consequence, smiling can in fact be a socially desired state (Gill et al., 2014). In view of the above, we assumed that having distinct physical facial features would serve as a strong determinant of formulated judgments, while smiling would serve as a secondary and merely complementary function in this process. Namely, we predicted that a smiling expression would hinder the visibility of facial features and thus a smile should result in a more positive evaluation 
of trust. When facial cues suggest the "presence" of a given trait (e.g., trustworthiness), a smile should not alter the judgment.

To test the above assumptions, we ran two experiments in which participants were presented with manipulated photographs of faces (generated by the computer as well as real ones) and were asked to evaluate them. Faces used in the experiments were manipulated in a factorial manner on two levels: (1) static features: eliciting trust or not by manipulating the physical features of the face (see Todorov et al., 2008) in Experiment 1 and by enhancing or not enhancing the physical resemblance to the assessing person in Experiment 2; (2) dynamic features: smiling vs. a neutral emotional expression.

\section{EXPERIMENT 1}

\section{METHOD}

Participants. Thirty-three undergraduate students ( 22 females, age was not recorded) of the SWPS University of Social Sciences and Humanities in Warsaw volunteered to participate in this experiment in exchange for course credit. A post-hoc power analysis for repeated measures ANOVA, performed with $G^{*}$ Power software (Faul, Erdfelder, Lang, \& Buchner, 2007), indicated that this sample was sufficient to detect an effect size of $f>.2$ (small effect; Cohen, 1988 ) with a power of $1-\beta>.8$.

Stimuli. We used eight male identities taken from a face stimuli database (Todorov, Dotsch, Porter, Oosterhof, \& Falvello, 2013). Facial identities were manipulated along the dimensions of dominance or trustworthiness on both shape and reflectance. A description of how the models of these dimensions were created is provided in Oosterhof \& Todorov (2008) and Todorov \& Oosterhof (2011). Each identity was presented as maximally distinct on either high or low trustworthiness ratings and on either high or low dominance (Oosterhof \& Todorov, 2008; Todorov \& Oosterhof, 2011). Additionally, using the FaceGen Modeller program, we generated two versions of each identity: a distinct neutral vs. positive emotion display (i.e., neutral vs. smiling expression; see Figure 1 for a sample of the stimuli). This resulted in 32 individual faces used as stimuli.

Procedure. The participants completed the computerized procedure individually and performed 64 trials, which were preceded by four warm-up trials (all conditions were counterbalanced and presented randomly on a within-subject 
basis). Each trial started with a fixation point that was followed by a single face presented for 3 seconds. After each face, the participants were asked to answer two questions: "Is this person trustworthy?" (in Polish: "Czy tej osobie można zaufać?"; trust/communion dimension; Abele \& Wojciszke, 2014; Todorov et al., 2009) and "Is this person confident?" (in Polish: "Czy ta osoba jest pewna siebie?"; dominance/agency dimension; Abele \& Wojciszke, 2014; Oosterhof \& Todorov, 2008). They indicated their judgments on a 100-point axis (anchored with "no" and "yes" labels), using a computer mouse to confirm their evaluations.

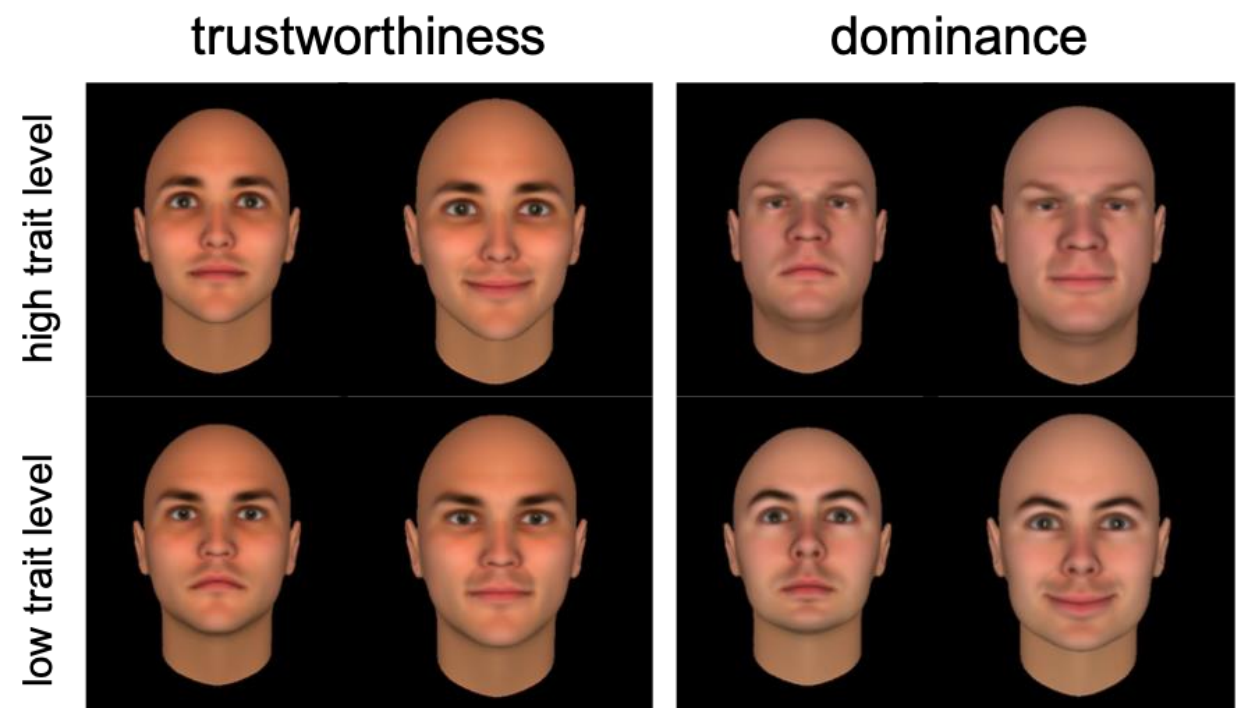

Figure 1. Sample of the stimuli used in Experiment 1. Identities are maximally distinct on either high or low ratings of trustworthiness (left panel) and high or low dominance (right panel) (Oosterhof \& Todorov, 2008; Todorov \& Oosterhof, 2011). Two versions of each identity were generated - a distinct neutral display and a positive emotion display.

\section{RESULTS}

The measures of trustworthiness and dominance judgments were analyzed separately in a 2 (domain: trust vs. dominance) x 2 (trait level: low vs. high) x 2 (emotional expression: neutral vs. smile) repeated measures ANOVA. Descriptive statistics for each condition are presented in Table 1 . 
For the trustworthiness judgments we found a significant main effect of emotional expression, as smiling faces were rated as more trustworthy than those with a neutral display $F(1,32)=18.16, p<.001, \eta_{\mathrm{p}}{ }^{2}=.36$. Additionally, faces manipulated on the trust dimension were rated as more trustworthy than faces manipulated on dominance, $F(1,32)=14.09, p<.001, \eta_{\mathrm{p}}{ }^{2}=.31$. Importantly, these effects were qualified by a significant interaction of domain, trait level, and expression, $F(1,32)=67.04, p<.001, \eta_{\mathrm{p}}{ }^{2}=.67$. To better understand the nature of the observed dependencies, we conducted a 2 (trait level) x 2 (emotional expression) analysis for faces manipulated on the trustworthiness and dominance domains separately. Faces with trustworthy features were rated as trustworthy despite their facial display, while faces low on trustworthiness were judged as significantly more trustworthy when smiling, $F(1,32)=18.09, p<.001$, $\eta_{\mathrm{p}}{ }^{2}=.36$. Additionally, we observed a main effect of facial expression, $F(1,32)=$ $=6.58, p<.016, \eta_{\mathrm{p}}{ }^{2}=.17$, which means that smiling faces were rated as more trustworthy than neutral ones, and a main effect of face dimension level, $F(1,32)=65.61, p<.001, \eta_{\mathrm{p}}{ }^{2}=.67$, showing that faces with highly trustworthy features were rated as more trustworthy than those with low trustworthy features. A similar analysis conducted on faces manipulated on the dominance dimension revealed only two main effects: again, smiling faces were rated as more trustworthy than neutral ones, $F(1,32)=27.43, p<.001, \eta_{\mathrm{p}}{ }^{2}=.46$, and high-dominant faces were perceived as less trustworthy than low-dominant faces, $F(1,32)=44.96, p<.001, \eta_{\mathrm{p}}{ }^{2}=.58$.

Similarly, for the confidence judgments we found a significant effect of emotional expression, $F(1,32)=26.99, p<.001, \eta_{\mathrm{p}}{ }^{2}=.36$, which means that smiling faces were rated as more confident than neutral faces. Also faces with a high level of either trait (dominance or trust) were rated as more confident than those with a low level of trait features $F(1,32)=17.91, p<.001, \eta_{\mathrm{p}}{ }^{2}=.36$. Here we also found the same significant interaction of domain, trait level, and expression, $F(1,32)=5.86, p<.022, \eta_{\mathrm{p}}{ }^{2}=.16$, and therefore, again, we conducted a separate analysis for each manipulated dimension. When comparing high- and low-trustworthy faces we noticed only two main effects. Highly trustworthy faces were rated as less confident than low-trustworthy faces, $F(1,32)=12.66$, $p<.002, \eta_{\mathrm{p}}{ }^{2}=.28$, and smiling faces were rated as more confident than neutral ones, $F(1,32)=19.92, p<.001, \eta_{\mathrm{p}}{ }^{2}=.38$. Faces manipulated on the dominance dimension were rated as more dominant when smiling, $F(1,32)=24.25$, $p<.001, \eta_{\mathrm{p}}^{2}=.43$, and when having dominant features, $F(1,32)=48.78$, $p<.001, \eta_{\mathrm{p}}^{2}=.60$. Importantly, there was a significant interaction, $F(1,32)=$ $=9.86, p<.004, \eta_{\mathrm{p}}{ }^{2}=.24$, showing that there was a robust effect of smiling for 
faces low in dominance, $F(1,32)=28.79, p<.001, \eta_{\mathrm{p}}{ }^{2}=.47$, while this effect was only marginally significant when faces were already highly dominant, $F(1,32)=4.23, p<.048, \eta_{\mathrm{p}}{ }^{2}=.12$.

Table 1. Means and Standard Deviations (SD, in Parentheses) for Trust and Confidence Ratings in Experiment 1

Trust Ratings

\begin{tabular}{|c|c|c|c|c|c|c|c|}
\hline \multirow{2}{*}{$\begin{array}{c}\text { Domain } \\
\text { Trait level }\end{array}$} & \multirow{2}{*}{\multicolumn{2}{|c|}{$\begin{array}{c}\text { Trust } \\
\text { High } \\
M(S D)\end{array}$}} & \multicolumn{5}{|c|}{ Dominance } \\
\hline & & & & $\begin{array}{c}\text { Low } \\
M(S D)\end{array}$ & $\begin{array}{c}\text { High } \\
M(S D)\end{array}$ & & \\
\hline Neutral & $\begin{array}{c}36.24 \\
(12.19)\end{array}$ & $\begin{array}{c}56.23 \\
(13.45)\end{array}$ & $\begin{array}{c}46.24 \\
(11.05)\end{array}$ & $\begin{array}{c}48.08 \\
(13.27)\end{array}$ & $\begin{array}{c}31.60 \\
(15.12)\end{array}$ & $\begin{array}{c}39.84 \\
(11.79)\end{array}$ & $\begin{array}{l}41.03 \\
(8.02)\end{array}$ \\
\hline \multirow[t]{2}{*}{ Smile } & $\begin{array}{c}47.69 \\
(14.32)\end{array}$ & $\begin{array}{c}56.54 \\
(16.79)\end{array}$ & $\begin{array}{c}52.12 \\
(14.34)\end{array}$ & $\begin{array}{c}57.39 \\
(15.24)\end{array}$ & $\begin{array}{c}37.60 \\
(16.09)\end{array}$ & $\begin{array}{c}47.50 \\
(12.96)\end{array}$ & $\begin{array}{l}52.94 \\
(9.76)\end{array}$ \\
\hline & $\begin{array}{l}41.97 \\
(10.28)\end{array}$ & $\begin{array}{c}56.39 \\
(13.70)\end{array}$ & $\begin{array}{c}49.18 \\
(10.98)\end{array}$ & $\begin{array}{c}52.74 \\
(13.13)\end{array}$ & $\begin{array}{c}34.61 \\
(14.83)\end{array}$ & $\begin{array}{c}43.68 \\
(11.65)\end{array}$ & \\
\hline \multicolumn{8}{|c|}{ Confidence Ratings } \\
\hline Domain & & Trust & \multicolumn{5}{|c|}{ Dominance } \\
\hline Trait level & $\begin{array}{l}\text { Low } \\
M(S D)\end{array}$ & $\begin{array}{c}\text { High } \\
M(S D)\end{array}$ & & $\begin{array}{c}\text { Low } \\
M(S D)\end{array}$ & $\begin{array}{c}\text { High } \\
M(S D)\end{array}$ & & \\
\hline Neutral & $\begin{array}{c}53.89 \\
(13.71)\end{array}$ & $\begin{array}{l}47.17 \\
(9.47)\end{array}$ & $\begin{array}{c}50.53 \\
(10.51)\end{array}$ & $\begin{array}{c}38.58 \\
(\mathbf{1 1 . 2 3})\end{array}$ & $\begin{array}{c}58.34 \\
(16.13)\end{array}$ & $\begin{array}{c}48.46 \\
(11.58)\end{array}$ & $\begin{array}{c}49.49 \\
(10.68)\end{array}$ \\
\hline \multirow[t]{2}{*}{ Smile } & $\begin{array}{c}58.16 \\
(13.69)\end{array}$ & $\begin{array}{c}52.75 \\
(13.24)\end{array}$ & $\begin{array}{c}55.46 \\
(11.69)\end{array}$ & $\begin{array}{c}51.01 \\
(12.32)\end{array}$ & $\begin{array}{c}62.35 \\
(14.38)\end{array}$ & $\begin{array}{c}56.68 \\
(11.25)\end{array}$ & $\begin{array}{c}56.07 \\
(11.27)\end{array}$ \\
\hline & $\begin{array}{c}56.02 \\
(12.74)\end{array}$ & $\begin{array}{c}49.96 \\
(10.61)\end{array}$ & & $\begin{array}{r}44.79 \\
(9.73)\end{array}$ & $\begin{array}{c}60.35 \\
(14.22)\end{array}$ & & \\
\hline
\end{tabular}

\section{DISCUSSION}

This study has confirmed that a smiling expression serves as a crucial dynamic influence when formulating both communal and agentic judgments, but the contextual impact of such impression are changeable depending upon the assessed person's static facial features. Relying merely on situational expressions (which can be contextually changed) should not be enough for the optimal judgment of static characteristics. Importantly, when facial features imply trust the influence of the smile is significantly reduced.

One could argue that an alternative explanation for such an effect would be that in Experiment 1 we manipulated the morphological features of trust that resemble emotional displays (see Oosterhoff \& Todorov, 2009). In order to dis- 
entangle these possible sources of conflating smiles, we decided that in Experiment 2 we needed to introduce a different method to influence static facial features of trust that would result with an unchanged emotional expression. One way to reach that goal would be to manipulate the idiosyncratic typicality of perceived faces - a potential cue for kinship (DeBruine, 2005). As previous research suggests (Andersen \& Baum, 1994; Andersen \& Cole, 1990), at first sight people like and trust others who resemble the people they like and trust already (e.g., self). Also, it has been shown that face resemblance increases trusting behavior (DeBruine, 2002) as well as a self-reported preference for children (Platek, Burch, Panyavin, Wasserman, \& Gallup, 2002; DeBruine, 2004). Thus, in Experiment 2 we decided to manipulate the level of self-resemblance. We manipulated physical similarity to participants' own face.

\section{EXPERIMENT 2}

When making judgments about others, people take into account the available cues of their physical familiarity. They tend to more positively evaluate faces resembling their own, in comparison to dissimilar ones (Bailenson, Iyengar, Yee, \& Collins, 2008; DeBruine, 2002, 2005); they also acquire affective associations with familiar faces, which they later generalize to strange ones (Verosky \& Todorov, 2010, 2013). In this study we asked individuals to perform a similar procedure as in Experiment 1, but this time we manipulated the trustworthiness of faces using cues of familiarity. Specifically, half of the presented faces were morphed with pictures of the participants, thus constituting a self-resemblance condition (as shown in Figure 2).

\section{METHOD}

Participants. Thirty undergraduate students (17 females, age was not recorded) from the SWPS University of Social Sciences and Humanities in Warsaw volunteered to participate in this experiment in exchange for course credit. A post hoc power analysis for repeated measures ANOVA, performed with G*Power software (Faul et al., 2007), indicated that the sample was sufficient to detect an effect size of $f>.22$ (intermediate effect; Cohen, 1988) with a power of 1- $\beta>.8$.

Stimuli. We used pictures of 20 individuals (10 males and 10 females) taken from the Warsaw Set of Emotional Facial Expression Pictures (WSEFEP; 
Olszanowski et al., 2015). Each of them provided two facial expressions (neutral and happy; 40 pictures in total), and for each participant we created two groups of pictures: self-resembling and non-resembling. To create resembling faces, we morphed the picture of each participant's face (taken a few weeks before the experiment by another experimenter under a false pretense of a pilot study regarding facial features) with the face of an individual of the same gender using Fanta Morph 5 software. Morphing templates consisted of approx. 100 anatomically defined points, while composite stimuli were created by sharing $50 \%$ of both shape and color information of the participant's face and the respective other's (smiling or neutral) face. The hair and neck regions of the composite face were masked.

For non-resembling faces we first made a prototype face of a stranger (separately for males and females) that was a composite portrait of 14 individuals, e.g., photographs of different subjects were combined based on templates consisting of approx. 100 points in regard to face shape and texture to produce a single blended image that represented a face with averaged features. Then we morphed this portrait with pictures of individuals, taking morphs containing 50\% of the prototype. As a result, for each participant, there were 20 pictures of "family members" (10 neutral and 10 smiling) and 20 pictures of "non-family members" (10 neutral and 10 smiling).

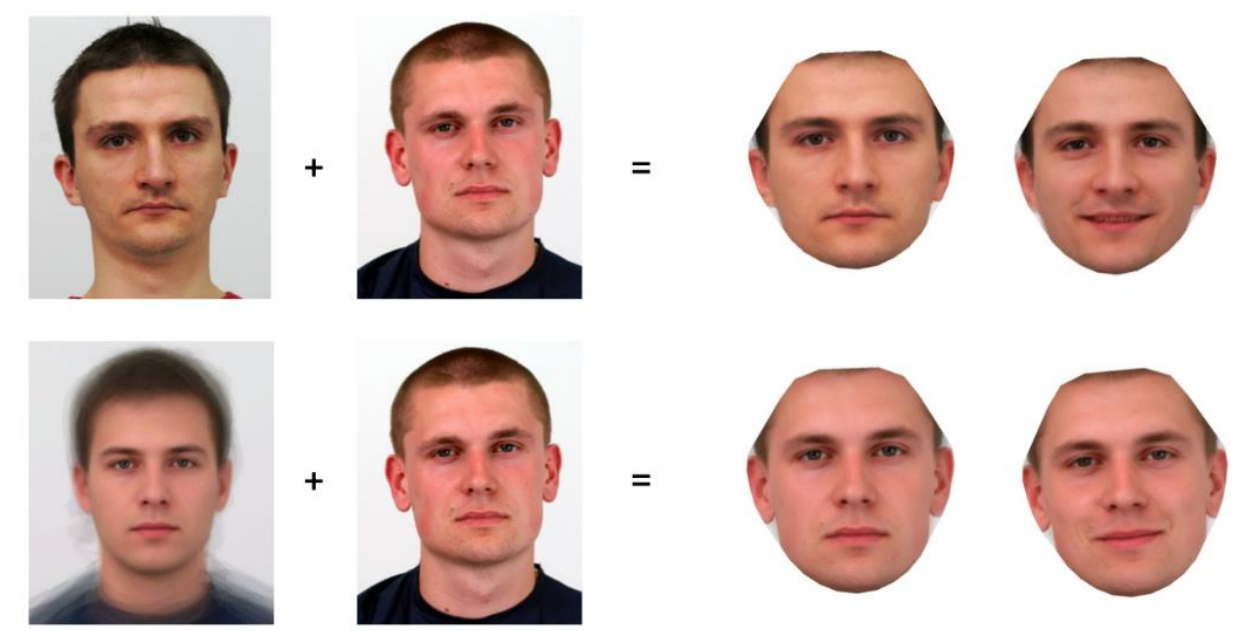

Figure 2. Sample of the stimuli used in Experiment 2. We morphed the picture of the participant's face (top panel) or a composite portrait of 14 individuals (bottom panel) with faces of individuals. Two versions of each identity were generated - a distinct neutral display and a positive emotion display. 
Procedure. The experimental procedure was designed as within-subject. The participants were introduced to the evaluation task and performed 40 trials, preceded by four warm-up trials. Each trial started with a fixation point that was followed by a face presented for 3 seconds, and then the participants answered two questions: "Is this person trustworthy?" (trust/communion dimension) and "Is this person confident?" (dominance/agency dimension). They indicated their judgments on a 100-point axis (anchored with "no" and "yes" labels) using a computer mouse to confirm their evaluations. After completing the study, the participants were fully debriefed and interviewed regarding their awareness of the experimental manipulation.

\section{RESULTS}

The data of five participants (four females) were excluded due to their awareness of the familiarity manipulation. The remaining data were analyzed using a 2 (self-resemblance: yes vs. no) x 2 (expression: neutral vs. smile) repeated measures ANOVA, separately for each type of evaluation. We found a significant interaction for perceptions of trustworthiness, $F(1,24)=8.50$, $p<.01, \eta_{\mathrm{p}}{ }^{2}=.26$. As can be seen in the left panel of Figure 3, the influence of facial expression differed depending on who was smiling. The participants showed more trust towards neutral self-resembling faces $(M=48.99, S D=$ $=10.14)$ than towards neutral non-resembling ones $(M=45.33, S D=8.06)$, while there was no difference in perceived trustworthiness for happy faces $\left(M_{\text {self-resembling }}=61.20, S D=12.97\right.$ vs. $\left.M_{\text {non-resembling }}=63.23, S D=10.83\right)$. Also, happy faces were judged as more trustworthy than neutral ones $\left(M_{\text {smile }}=62.22\right.$, $S D=10.68$ and $\left.M_{\text {neutral }}=47.16, S D=8.49\right), F(1,24)=27.60, p<.001, \eta_{\mathrm{p}}{ }^{2}=.54$, while there was no main effect for face familiarity, $F<1$. Similarly, the analysis of the confidence judgments revealed only a main effect of emotional expression (Figure 3, right panel), indicating that smiling faces were rated as more confident than neutral ones $\left(M_{\text {neutral }}=52.36, S D=9.15\right.$ vs. $\left.M_{\text {smile }}=63.64, S D=9.54\right)$, $F(1,24)=15.60, p<.01, \eta_{\mathrm{p}}^{2}=.39$. 

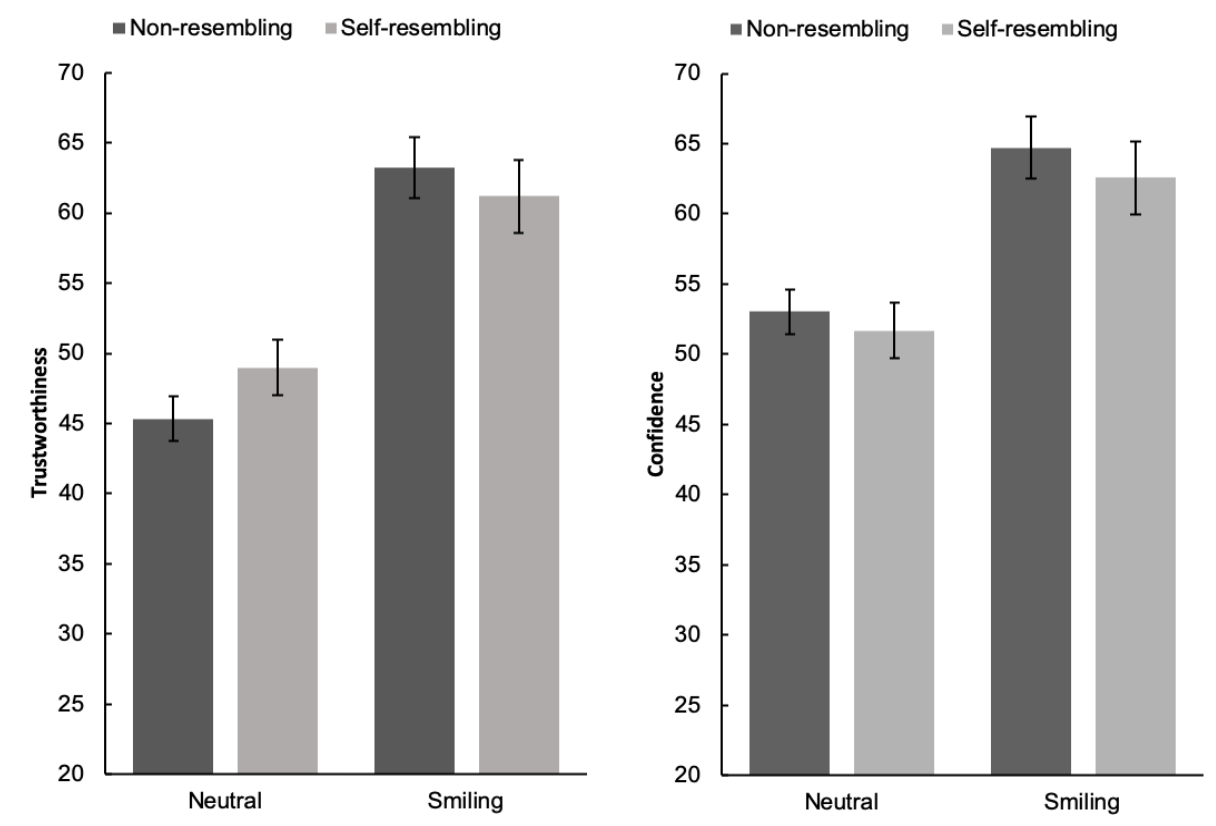

Figure 3. Ratings of trustworthiness (left panel) and dominance (right panel) for faces that are self-resembling (light-grey bars) and non-resembling (dark-grey bars) in Experiment 2. Both scales ranged from 1 to 100. Error bars depict SEM.

\section{DISCUSSION}

As predicted, Study 2 suggests that physical resemblance to one's own face is a strong cue for favoritism in social judgments, especially those made on a communal dimension. More specifically, self-resembling faces benefit less from positive emotional expression in cases of communal judgments (e.g., trustworthiness), whereas agency judgments (e.g., confidence) rely on facial expression to a larger degree. Importantly, as the participants were not aware of the facial resemblance, the unconscious preference for familiar-looking faces seems to have been confirmed. This preference also lends support to the postulated mechanism of kinship detection (DeBruine, 2004, 2005). It should be noted that such a preference was observed for a communion-related trait (trustworthiness), but not for an agency-related trait (confidence). This can be explained by the primacy of communion over agency in judgments about unknown persons, as traits related to a communal dimension make it possible to predict the personal consequences of interactions better (Wojciszke \& Abele, 2008). 


\section{SUMMARY AND CONCLUSIONS}

The aim of the presented studies was to investigate the interplay between the dynamic (i.e., a smiling expression) and static (physical features) factors in social judgments. First, we wanted to test the hypotheses pertaining to the assumptions made by Todorov et al. (2008), who developed a statistical model of basic facial features. These features constitute the foundation for evaluating faces on the social dimensions of valence/trustworthiness and power/dominance. The evaluation of those features largely depends on changing many specific arrangements of facial features; for trustworthiness the crucial ones are those that resemble an emotional expression of anger (e.g., prominent eyebrows, thin lips, droopy mouth corners) or joy (arching eyebrows, full mouth or mouth corners lifted), while judging dominance depends on physical strength (e.g., a strong chin or mandible bones). In our experiments, we tested how these facial cues influence inferences about communal and agentic traits in the context of smiling. We showed that smiling faces were rated more positively on traits associated with both communal (i.e., trust) and agentic (i.e. confidence) dimensions. However, when faces were physically manipulated in a way that highlighted trust or dominant features, the role of emotional expression decreased. In other words, it seems that when facial features signal trustworthiness or dominance, the facial display matters less for the respective judgments.

Secondly, we wanted to investigate the dynamics of the familiarity of the perceived person in the evaluation of communal and agentic traits. Based on the research conducted by Verosky and Todorov (2010) as well as by Jones and colleagues (Jones, DeBruine, Little, \& Feinberg, 2007), we predicted that people would transfer their positive self-associations and assessments to the observed individuals, providing they looked similar. We confirmed, again, that smiling led to more positive evaluations, but at the same time we found that the impact of a smile was reduced when respective physical features were visible. As people generally trust themselves and their family members, self-resembling faces were rated as more trustworthy, independently of the smile. We did not observe an impact of face similarity on confidence judgments, but further studies on self-resemblance should include additional measurements of agency-related traits to control for any variance in that matter. It is possible that there is no effect for confidence ratings (as confidence seems to be highly context-dependent), but we would find one for intelligence ratings, intelligence being presumably more stable over time. 
Importantly, people do not seem to be subjectively aware of the fact that the similarity between faces appears at all. Essentially, the analyzed participants did not detect any similarity to their own face or to the faces they had seen before (an unobtrusive manipulation of trust). On the one hand, this may suggest that positive attitude could be a simple result of mere repeated exposure to the sight of one's own face (Zajonc, 1968). However, it should be noted that some studies (DeBruine, 2002, 2005; DeBruine, Jones, \& Perrett, 2005) indicate that the evaluation of self-resembling faces is not necessarily related to the effect of repeated exposure, as these faces are rated higher on trust but not on sexual attractiveness compared to non-resembling faces. Such differential impacts suggest the existence of specialized processing of cues of kinship in the form of facial resemblance other than just a general preference for familiar stimuli (Andersen \& Cole, 1990).

It is worth mentioning here that there are differences in the meaning of a smile that could also influence the analyzed judgments. As recent studies show, a smile can signal different types of behavior depending on both the situational context and the way in which it was expressed (e.g., on whether the facial display includes brow raising or nose wrinkling). The meaning it carries may signal affiliation, but it may also convey social reward or even dominance (Rychlowska et al., 2017). Yet, in respect to the facial patterns described in the aforementioned work, smiles in our experiment were rather affiliative and rewarding in nature. We can only speculate at this point that dominant faces are more likely to be perceived as wearing a dominant rather than affiliative smile. Further research is needed to confirm whether this is the case. Moreover, it could be interesting to extend the spectrum of facial expressions used as stimuli. As has already been shown in other studies, angry faces are perceived as more dominant (Hess, Blairy, \& Kleck, 2000; Knutson, 1996; Montepare \& Dobish, 2003). In line with current findings, it could then be expected that dominant faces would not be perceived as more dominant by being angry.

A certain limitation of the current studies must be mentioned here. First of all, all judgments we used were purely declarative, which raises the following question: to what extent would those declaratives translate into real affiliative behaviors (Doliński, 2018)? As a matter of fact some of the previous studies have already provided causal evidence that facial appearances influence voting preferences (Olivola, Sussman, Tsetsos, Kang, \& Todorov, 2012), legal judgments (Wilson \& Rule, 2015), and economic exchanges (Rezlescu, Duchaine, Olivola, \& Chater, 2012; Bonnefon, \& Hopfensitz, 2013). Another line of research suggests that facial cues inducing trust behaviors can be observed even in very 
young children (Ewing, Caulfield, Read, \& Rhodes, 2015). However, further studies should use more naturalistic measurements that would allow judgments to be directly connected with behavior, such as economic "trust games," where participants needs to share money/points with other players according to their beliefs about whether or not the other player will give the money/points back (Berg, Dickhaut, \& McCabe, 1995).

We can conclude that facial expression is more readily available perceptively than physical features indicating traits and that, as such, it facilitates the process of trait inference. As a result, a smile causes more positive evaluations, which confirms previous findings (e.g., Winkielman et al., 2015). Thus, paradoxically, although emotional expression is linked to dynamically changing situational factors (which means it should be a less reliable indicator of stable personality traits), it affects judgments of traits related to communal dimensions. Importantly, physical features attenuate the impact of a facial display, supporting one of our main expectations that the dynamics of a smile would differ depending on the type of judgment and familiarity of physical properties perceived from a face. In sum, our results highlight the importance of the interaction of physical facial features and facial expression on social evaluations. This is consistent with other studies that show robust effects of facial appearance even after brief exposure (Todorov et al., 2009) or visual preference for trustworthy faces in primates (e.g., macaque monkeys; Costa et al., 2018), confirming the existence of inherited mechanisms for impressions based on trait-related facial cues. As current theoretical works suggest, such a mechanism can be based on bottom-up processes that associate similarity between facial features with trait concepts (e.g., connecting a mouth shape resembling a smile with trustworthiness; Stolier, Hehman, $\&$ Freeman, 2018).

\section{REFERENCES}

Abele, A. E., \& Wojciszke, B. (2007). Agency and communion from the perspective of self versus others. Journal of Personality and Social Psychology, 93(5), 751.

Abele, A. E., \& Wojciszke, B. (2014). Communal and agentic content in social cognition: A Dual Perspective Model. Advances in Experimental Social Psychology, 50, 195-255. DOI: 10.1016/B978-0-12-800284-1.00004-7

Andersen, S. M., \& Baum, A. (1994). Transference in interpersonal relations: Inferences and affect based on significant-other representations. Journal of Personality, 62(4), 459-497. DOI: 10.1111/j.1467-6494.1994.tb00306.x

Andersen, S. M., \& Cole, S. W. (1990). "Do I know you?" The role of significant others in general social perception. Journal of Personality and Social Psychology, 59(3), 384-399. 
Bailenson, J. N., Iyengar, S., Yee, N., \& Collins, N. A. (2008). Facial similarity between voters and candidates causes influence. Public Opinion Quarterly, 75(5), 935-961. DOI: 10.1093/ poq/nfn06

Berg, J., Dickhaut, J., \& McCabe, K. (1995). Trust, reciprocity, and social history. Games and Economic Behavior, 10(1), 122-142. DOI: 10.1006/game.1995.1027

Bonnefon, J. F., Hopfensitz, A., \& De Neys, W. (2013). The modular nature of trustworthiness detection. Journal of Experimental Psychology: General, 142, 143-150. DOI: 10.1037/a 0028930

Bruce, V., \& Young, A. (2012). Face perception. London: Psychology Press.

Cohen, J. (1988). Statistical power analysis for the behavioral sciences (2nd ed.). Hillsdale, NJ, US: Erlbaum.

Costa, M., Gomez, A., Barat, E., Lio, G., Duhamel, J. R., \& Sirigu, A. (2018). Implicit preference for human trustworthy faces in macaque monkeys. Nature Communications, 9(1), 4529. DOI: 10.1038/s41467-018-06987-4

Crivelli, C., \& Fridlund, A. J. (2018). Facial displays are tools for social influence. Trends in Cognitive Sciences, 22(5), 388-399. DOI: 10.1016/j.tics.2018.02.006

DeBruine, L. M. (2002). Facial resemblance enhances trust. Proceedings of the Royal Society of London Series B: Biological Sciences, 269(1498), 1307-1312. DOI: 10.1098/rspb.2002.2034

DeBruine, L. M. (2004). Resemblance to self increases the appeal of child faces to both men and women. Evolution \& Human Behavior, 25, 142-154. DOI: 10.1016/j.evolhumbehav. 2004.03.003

DeBruine, L. M. (2005). Trustworthy but not lust-worthy: Context-specific effects of facial resemblance. Proceedings of the Royal Society of London Series B: Biological Sciences, 272(1566), 919-922. DOI:10.1098/rspb.2004.3003

DeBruine, L. M., Jones, B. C., \& Perrett, D. I. (2005). Women's attractiveness judgments of self-resembling faces change across the menstrual cycle. Hormones and Behavior, 47(4), 379383. DOI: 10.1016/j.yhbeh.2004.11.006

Doliński, D. (2018). Is psychology still a science of behaviour? Social Psychological Bulletin, 13(2), e25025. DOI: $10.5964 /$ spb.v13i2.25025

Ekman, P. (2007). Emotions revealed: Recognizing faces and feelings to improve communication and emotional life. New York, NJ, US: Henry Holt and Company.

Ewing, L., Caulfield, F., Read, A., \& Rhodes, G. (2015). Perceived trustworthiness of faces drives trust behaviour in children. Developmental Science, 18(2), 327-334. DOI: 10.1111/desc.12218

Faul, F., Erdfelder, E., Buchner, A., \& Lang, A. G. (2009). Statistical power analyses using G* Power 3.1: Tests for correlation and regression analyses. Behavior Research Methods, 41(4), 1149-1160.

Fridlund, A. J. (1994). Human facial expression: An evolutionary view. San Diego: Academic Press.

Gill, D., Garrod, O. G. B., Jack, R. E., \& Schyns, P. G. (2014). Facial movements strategically camouflage involuntary social signals of face morphology. Psychological Science, 25(5), 1079-1086. DOI: $10.1177 / 0956797614522274$

Hassin, R., \& Trope, Y. (2000). Facing faces: Studies on the cognitive aspects of physiognomy. Journal of Personality and Social Psychology, 78(5), 837-852. DOI: 10.1037/00223514.78.5.837 
Haxby, J. V., Hoffman, E. A., \& Gobbini, M. I. (2000). The distributed human neural system for face perception. Trends in Cognitive Sciences, 4(6), 223-233. DOI: 10.1016/S1364-6613(00) 01482-0

Hehman, E., Flake, J. K., \& Freeman, J. B. (2015). Static and dynamic facial cues differentially affect the consistency of social evaluations. Personality and Social Psychology Bulletin, 41(8), 1123-1134. DOI: 10.1177/0146167215591495

Hess, U., Adams R. B., Jr., \& Kleck, R. E. (2009). The categorical perception of emotions and traits. Social Cognition, 27(2), 320-326. DOI: 10.1521/soco.2009.27.2.320

Hess, U., Blairy, S., \& Kleck, R. E. (2000). The influence of facial emotion displays, gender, and ethnicity on judgments of dominance and affiliation. Journal of Nonverbal Behaviour, 24, 265-283.

Horstmann, G. (2003). What do facial expressions convey: Feeling states, behavioral intentions, or action requests? Emotion, 3(2), 150-166. DOI: 10.1037/1528-3542.3.2.150

Jones, B. C., DeBruine, L. M., Little, A. C., \& Feinberg, D. R. (2007). The valence of experiences with faces influences generalized preferences. Journal of Evolutionary Psychology, 5(1), 119129. DOI: $10.1556 / \mathrm{JEP} .2007 .1001$

Knutson, B. (1996). Facial expressions of emotion influence interpersonal trait inferences. Journal of Nonverbal Behavior, 20(3), 165-182. DOI: 10.1007/BF02281954

Martin, J., Rychlowska, M., Wood, A., \& Niedenthal, P. (2017). Smiles as multipurpose social signals. Trends in Cognitive Sciences, 21(11), 864-877. DOI: 10.1016/j.tics.2017.08.007

Montepare, J. M., \& Dobish, H. (2003). The contribution of emotion perceptions and their overgeneralizations to trait impressions. Journal of Nonverbal Behavior, 27(4), 237-254. DOI: 10.1023/A:1027332800296

Olivola, C. Y., Sussman, A. B., Tsetsos, K., Kang, O. E., \& Todorov, A. (2012). Republicans prefer republican-looking leaders: Political facial stereotypes predict candidate electoral success among right-leaning voters. Social Psychological and Personality Science, 3(5), 605-613. DOI: $10.1177 / 1948550611432770$

Olszanowski, M., Kaminska, O. K., \& Winkielman, P. (2018). Mixed matters: Fluency impacts trust ratings when faces range on valence but not on motivational implications. Cognition and Emotion, 32(5), 1032-1051. DOI: 10.1080/02699931.2017.1386622

Olszanowski, M., Pochwatko, G., Kukliński, K., Ścibor-Rylski, M., Lewinski, P., \& Ohme, R. (2015). Warsaw set of emotional facial expression pictures: A validation study of facial display photographs. Frontiers in Psychology, 5(1516), 1-8. DOI: 10.3389/fpsyg.2014.01516

Oosterhof, N. N., \& Todorov, A. (2008). The functional basis of face evaluation. PNAS Proceedings of the National Academy of Sciences of the United States of America, 105(32), 11087-11092. DOI: 10.1073/pnas.0805664105

Oosterhof, N. N., \& Todorov, A. (2009). Shared perceptual basis of emotional expressions and trustworthiness impressions from faces. Emotion, 9(1), 128-133. DOI: 10.1037/a0014520.

Platek, S. M., Burch, R. L., Panyavin, I. S., Wasserman, B. H., \& Gallup, G. G., Jr (2002). Reactions to children's faces: Resemblance affects males more than females. Evolution \& Human Behavior, 23, 159-166. DOI: 10.1016/S1090-5138(01)00094-0

Rezlescu, C., Duchaine, B., Olivola, C. Y., \& Chater, N. (2012). Unfakeable facial configurations affect strategic choices in trust games with or without information about past behavior. PloS ONE, 7(3), e34293. DOI: 10.1371/journal.pone.0034293 
Rychlowska, M., Jack, R. E., Garrod, O. G. B., Schyns, P. G., Martin, J. D., \& Niedenthal, P. M. (2017). Functional smiles: Tools for love, sympathy, and war. Psychological Science, 28(9), 1259-1270. DOI: 10.1177/0956797617706082

Stolier, R. M., Hehman, E., \& Freeman, J. B. (2018). A dynamic structure of social trait space. Trends in Cognitive Sciences, 22(3), 197-200. DOI: 10.1016/j.tics.2017.12.003

Tanaka, J. W., \& Simonyi, D. (2016). The "parts and wholes" of face recognition: A review of the literature. The Quarterly Journal of Experimental Psychology, 69(10), 1876-1889.

Todorov, A. (2017). Face value: The irresistible influence of first impressions. Princeton, Oxford: Princeton University Press.

Todorov, A., Dotsch, R., Porter, J., Oosterhof, N., \& Falvello, V. (2013).Validation of data-driven computational models of social perception of faces. Emotion, 13(4), 724-738. DOI: 10.1037/a0032335

Todorov, A., \& Oosterhof, N. N. (2011). Modeling social perception of faces. IEEE Signal Processing Magazine, 28(2), 117-122. DOI: 10.1109/MSP.2010.940006

Todorov, A., Pakrashi, M., \& Oosterhof, N. N. (2009). Evaluating faces on trustworthiness after minimal time exposure. Social Cognition, 27(6), 813-833. DOI: 10.1521/soco.2009.27.6.813

Todorov, A., Said, C. P., Engell, A. D., \& Oosterhof, N. N. (2008). Understanding evaluation of faces on social dimensions. Trends in Cognitive Sciences, 12(12), 455-460. DOI: 10.1016/ j.tics.2008.10.001

Todorov, A., \& Uleman, J. S. (2003). The efficiency of binding spontaneous trait inferences to actors' faces. Journal of Experimental Social Psychology, 39(6), 549-562. DOI: 10.1016/ S0022-1031(03)00059-3

Van Kleef, G. A., Van Doorn, E. A., Heerdink, M. V., \& Koning, L. F. (2011). Emotion is for influence. European Review of Social Psychology, 22(1), 114-163. DOI: 10.1080/10463283. 2011.627192

Verosky, S. C., \& Todorov, A. (2010). Generalization of affective learning about faces to perceptually similar faces. Psychological Science, 21(6), 779-785. DOI: $10.1177 / 0956797610371965$

Verosky, S. C., \& Todorov, A. (2013). When physical similarity matters: Mechanisms underlying affective learning generalization to the evaluation of novel faces. Journal of Experimental Social Psychology, 49(4), 661-669. DOI: 10.1016/j.jesp.2013.02.004

Wilson, J. P., \& Rule, N. O. (2015). Facial trustworthiness predicts extreme criminal-sentencing outcomes. Psychological Science, 26(8), 1325-1331. DOI: 10.1177/0956797615590992

Winkielman, P., Olszanowski, M., \& Gola, M. (2015). Faces in-between: Evaluations reflect the interplay of facial features and task-dependent fluency. Emotion, 15(2), 232-242. DOI: $10.1037 / \mathrm{emo} 0000036$

Wojciszke, B., \& Abele, A. E. (2008). The primacy of communion over agency and its reversals in evaluations. European Journal of Social Psychology, 38, 1139-1147. DOI: 10.1002/ejsp.549

Ybarra, O., Chan, E., Park, H., Burnstein, E., Monin, B., \& Stanik, C. (2008). Life's recurring challenges and the fundamental dimensions: An integration and its implications for cultural differences and similarities. European Journal of Social Psychology, 38, 1083-1092. DOI:10.1002/ejsp.559

Zajonc, R. B. (1968). Attitudinal effects of mere exposure. Journal of Personality and Social Psychology, 9(2, Pt.2), 1-27.

Zebrowitz, L. A., \& Montepare, J. M. (2008). Social psychological face perception: Why appearance matters. Social and Personality Psychology Compass, 2, 1497-1517. DOI: 10.1111/j.1751-9004.2008.00109.x 